\title{
International migration and adverse birth outcomes: role of ethnicity, region of origin and destination
}

\author{
Marcelo Luis Urquia, ${ }^{1}$ Richard Henry Glazier, ${ }^{2}$ Beatrice Blondel, ${ }^{3}$ Jennifer Zeitlin, ${ }^{3}$ \\ Mika Gissler, ${ }^{4}$ Alison Macfarlane, ${ }^{5}$ Edward Ng, ${ }^{6}$ Maureen Heaman, ${ }^{7}$ \\ Babill Stray-Pedersen, ${ }^{8}$ Anita J Gagnon, ${ }^{9}$ for the ROAM collaboration
}

\begin{abstract}
${ }^{1}$ Centre for Research on Inner City Health, St. Michael's Hospital, Toronto, Canada ${ }^{2}$ Institute for Clinical Evaluative Sciences, Toronto, Canada ${ }^{3}$ Epidemiological Research Unit on Perinatal Health and Women's Health (INSERM), Paris, France ${ }^{4}$ National Research and Development Centre for Welfare and Health (STAKES), Helsinki, Finland ${ }^{5}$ City University, London, UK ${ }^{6}$ Statistics Canada, Ottawa, Canada ${ }^{7}$ Faculty of Nursing, University of Manitoba, Winnipeg, Canada ${ }^{8}$ University of Oslo, Rikshospitalet, Oslo, Norway ${ }^{9}$ McGill University/MUHC, Montreal, Canada
\end{abstract}

\section{Correspondence to}

Dr Marcelo Luis Urquia, Centre for Research on Inner City Health, St Michael's Hospital, 70 Richmond Street E, 4th Floor, Toronto, ON M5C 1N8, Canada; marcelo.urquia@utoronto.ca

* See end of paper for members of the ROAM collaboration.

Accepted 16 May 2009

This paper is freely available online under the BMJ Journals unlocked scheme, see http:// jech.bmj.com/site/about/ unlocked.xhtml.

\section{ABSTRACT}

Background The literature on international migration and birth outcomes shows mixed results. This study examined whether low birth weight (LBW) and preterm birth differed between non-migrants and migrant subgroups, defined by race/ethnicity and world region of origin and destination.

Methods A systematic review and meta-regression analyses were conducted using three-level logistic models to account for the heterogeneity between studies and between subgroups within studies. Results Twenty-four studies, involving more than 30 million singleton births, met the inclusion criteria. Compared with US-born black women, black migrant women were at lower odds of delivering LBW and preterm birth babies. Hispanic migrants also exhibited lower odds for these outcomes, but Asian and white migrants did not. Sub-Saharan African and LatinAmerican and Caribbean women were at higher odds of delivering LBW babies in Europe but not in the USA and south-central Asians were at higher odds in both continents, compared with the native-born populations.

Conclusions The association between migration and adverse birth outcomes varies by migrant subgroup and it is sensitive to the definition of the migrant and reference groups.

Approximately 95 million women are international migrants worldwide and female immigrants have recently outnumbered men in most industrialised countries. ${ }^{1}$ Immigrant women currently contribute more than one fifth of all live births in the USA ${ }^{2}$ and several European countries. ${ }^{3}$ Despite a substantial body of literature focussing on the reproductive health of migrants to western industrialised countries, there is no obvious pattern describing the relation between migrant status and perinatal outcomes. The literature shows positive, negative and null associations between migration and perinatal health, suggesting that different sources of heterogeneity may play a role. It is uncertain to what extent the association between foreign-born status and birth outcomes is a function of the characteristics of the migrant populations, of the baseline risk of the native-born reference groups, or of some combination of both. For example, foreignborn black women in the USA compare favourably with US-born black women but not with US-born white women. ${ }^{4}$ Such comparisons suggest that the influence of migration may be modified by ethnicity. ${ }^{5}$ Ethnic disparities in birth outcomes are well documented, particularly in the USA, but the contribution of migration to these disparities is not well understood. In studies comparing native-born compared with migrant groups defined by their regions of origin, there is uncertainty over whether the so-called healthy migrant effect ${ }^{6}$ applies to migrants from all or only some regions of the world, and what these regions are.

ROAM (Reproductive Outcomes And Migration), an international research collaboration; members: Sophie Alexander (Université libre de Bruxelles, Belgium); Béatrice Blondel, (INSERM, France); Simone Buitendijk, (TNO Institute, Prevention and Care, The Netherlands); Marie Desmeules (Public Health Agency of Canada); Dominico Di Lallo (Agency for Public Health of Rome, Italy); Anita Gagnon (McGill University and MUHC, Canada); Mika Gissler (STAKES, Finland); Richard Glazier (Institute for Clinical Evaluative Sciences, Canada); Maureen Heaman (University of Manitoba, Canada); Dineke Korfker (TNO Institute, Prevention and Care, The Netherlands); Alison Macfarlane (City University of London, UK); Edward $\mathrm{Ng}$ (Statistics Canada); Carolyn Roth (Keele University, UK); Rhonda Small (La Trobe University, Australia); Donna Stewart (University Health Network of Toronto, University of Toronto, Canada); Babill Stray-Pedersen (University of Oslo, Norway); Marcelo Urquia (Institute for Clinical Evaluative Sciences, Canada); Siri Vangen (Department of Obstetrics and Gynaecology, The National Hospital of Norway); Jennifer Zeitlin (INSERM, France and EURO-PERISTAT); Meg Zimbeck (INSERM, France and EURO-PERISTAT).

In addition, the vast majority of the studies on migration and birth outcomes grouped women according to their ethnicity or their country of origin, but comparisons according to their country of destination have largely been neglected, with one recent European exception. ${ }^{7}$ Moreover, the interaction between sending and receiving countries has not previously been explored. International migration patterns may generate the selection of particular migrants from and to certain countries, thus leading to differential health outcomes among migrants from one particular world region settling in different receiving countries. Health differences may also arise as a result of exposure to contrasting receiving environments.

Most studies devoted to migration and perinatal health have focused on birth outcomes defined by birth weight or gestational age or both. Our purpose was to conduct a systematic review to clarify the relation between migration and these 
birth outcomes by determining the differences in low birth weight (LBW) and preterm birth (PTB) between migrants and non-migrants by migrant subgroups, defined according to race/ ethnicity, world region of origin and actual destination.

\section{METHODS}

This review was prepared following the MOOSE guidelines ${ }^{8}$ and draws on the material identified by the Reproductive Outcome And Migration (ROAM) collaboration for a series of systematic reviews on migration and reproductive health.

\section{Study population}

This study was restricted to published reports on any outcome requiring gestational age or infant birth weight to define it. The exposure was maternal international migration to western industrialised countries, assessed by evidence of cross-border movement. This definition thus excludes internal migration, 'protectorates' such as Puerto Rico and second-generation populations. Referent groups were the native-born women of the receiving countries and white women when comparisons were made between ethnic groups. We excluded case studies, clinical reports, reports without a comparison group and reports in which the results of the migrant group(s) were not presented separately from the comparison group.

\section{Search and study selection criteria}

Studies were identified through electronic literature databases from 1995 to October 2007 using Ovid (V.10.5.1) in the following order: Medline, Health Star, Embase and PsychInfo. Searches were supplemented with bibliographic citation hand searches of included articles published from 2004 onwards and relevant articles referred to the authors. No language exclusions were routinely applied. Articles in French, Italian and Spanish were reviewed by the authors. Two ROAM members independently assessed included studies for quality using the US Preventive Services Task Force criteria for cohort and casecontrol studies ${ }^{9}$ and no discrepancies were found in the overall score between raters.

All articles for the meta-analyses were selected by applying the following criteria:

1. Definitions of the outcomes: LBW was restricted to a birth weight less than $2500 \mathrm{~g}$ and PTB to a gestational age of less than 37 completed weeks. Due to the small number of studies it was not possible to choose a uniform definition of small for gestational age (SGA), and therefore SGA was dropped from further analysis. Varying definitions included SGA based on different percentiles of the birth weight distribution of nativeborn populations ${ }^{610-13}$ or standard deviations, ${ }^{14} 15$ full-term LBW infants ${ }^{16} 17$ and revealed SGA, based on the fetuses at-risk approach. ${ }^{18}$

2. Restriction to singleton births.

3. Information on race/ethnicity and foreign-born status or country of birth or nationality.

4. Descriptive tables including summary data on the outcomes with at least one native-born and one foreign-born group.

\section{Meta-analyses}

Studies differed substantially in the way migrant groups were categorised. Unlike the USA, where birth certificates include fields for parental race/ethnic origin and birthplace, ${ }^{19}$ the EU legislation discourages the collection and reporting of individual information on race/ethnicity. ${ }^{20}$ In the UK, ethnic origin is not collected in birth records but some studies linked them to the census, in which such information is recorded. ${ }^{21}$ European studies thus relied on country of birth or nationality to assess minority groups. These continental differences in the measurement of migrant groups prevented us from combining all selected studies into one single meta-analysis, and therefore we conducted two meta-analyses based on the two main approaches that have been used to study the influences of international migration on birth outcomes.

In the first approach, studies conducted in the USA used selfreported race/ethnicity and foreign-born status, ${ }^{19}$ but not necessarily maternal birthplace. These studies allowed the comparison of foreign-born versus native-born women of the same race/ethnicity. One UK study ${ }^{21}$ also reported these data for LBW but was excluded to restrict our analysis to the US context. We also excluded Hispanic women from one US study ${ }^{5}$ to avoid data duplication with another study. ${ }^{6}$

In the second approach, several studies conducted in Europe compared all migrants or migrants from particular regions of the world with the native-born population without reference to ethnic group (table 1). This second meta-analysis excluded some US studies that did not provide information at the country level. In one study that stratified the outcomes by Asian countries of origin but not by foreign-born status, we considered as foreignborn those national-origin groups with at least $90 \%$ of foreignborn women and therefore excluded Japanese and Filipino women. ${ }^{22}$ One UK study ${ }^{21}$ was removed to avoid data duplication with another national study. ${ }^{23}$

Our searches identified 82 studies. Of these, we excluded 11 studies that did not include LBW or PTB or used different definitions, ${ }^{10}{ }^{24-33} 31$ studies that did not discriminate between singleton and multiple births, ${ }^{2}{ }^{34-63}$ four that did not ascertain migration appropriately ${ }^{64-67}$ and seven that did not have appropriate tables for the extraction of the data. ${ }^{68-74}$ Finally, five studies reporting PTB by world region of birth were not used due to the small number of studies available for this outcome using the second approach. ${ }^{14} 15$ 75-77 Therefore, 24 studies were included in the meta-analyses: 16 by race/ethnicity (table 2) ${ }^{4-6} 121316-1878-8516$ by world region (table 1$)^{4} 611-13$ $16172223818385-89$ and nine by both. ${ }^{4} 612131617818385$ None of the selected studies had poor internal validity. ${ }^{9}$

\section{Data extraction}

For each outcome, we extracted summary birth data consisting of at least two records per study: one for the migrant and one for the native-born group, although many studies included several subgroups including maternal ethnic groups, world regions or countries of origin or infants' year of birth. Each record contained a numerator and a denominator for the outcome and indicators of migrant status (foreign-born, native-born), race/ethnicity as categorised in US studies (Asians, blacks, Hispanics and whites) ${ }^{19}$ migrants' country of birth or origin or nationality, place of destination (US or European countries) and infants' year of birth. If the birth data aggregated more than one year, the midpoint was recorded, and for articles reporting numerators and denominators for different periods, one record was assigned to each period. We grouped countries of birth into world regions, following the classification of the United Nations in most cases. ${ }^{90}$ Asia was subdivided into south-central Asia (mainly India, Pakistan and Bangladesh) and east/south-east Asia, because women from the Indian subcontinent may differ in the risk of adverse birth outcomes compared with the rest of Asia. ${ }^{91}$ In the same vein, north Africans were separated from the rest of Africa (ie, sub-Saharan Africa) because of their particularly good birth outcomes, ${ }^{87}$ and were grouped with Middle Eastern 
Table 1 Characteristics of the studies included in the meta-analysis of LBW by world regions

\begin{tabular}{|c|c|c|c|c|c|c|c|}
\hline Study & Country, state/region & $\begin{array}{l}\text { Type of } \\
\text { database }\end{array}$ & $\begin{array}{l}\text { Year of } \\
\text { data }\end{array}$ & Migrants' world regions & $\begin{array}{l}\text { No of } \\
\text { subgroups }\end{array}$ & Births & $\%$ Migrants \\
\hline Buekens/1998 & Belgium, national & PBR & $1981-8$ & North Africa & 2 & 838972 & 4.1 \\
\hline Collinwood-Bakeo/2004 & UK, national & PBR & 1983-2001 & $\begin{array}{l}\text { Caribbean, East Africa, West Africa, } \\
\text { south-central Asia, east Europe, western } \\
\text { Europe }\end{array}$ & 55 & 11401247 & 8.0 \\
\hline Crump/1999 & USA, Washington State & PBR & $1989-94$ & Latin America (Mexico) & 2 & 9572 & 50.0 \\
\hline David/1997 & USA, Illinois State & PBR & $1980-95$ & Sub-Saharan Africa & 3 & 90503 & 3.5 \\
\hline Fuentes-Afflick/1997 & USA, California State & PBR & 1992 & $\begin{array}{l}\text { Cambodia, China, India, Korea, Laos, } \\
\text { Thailand, Vietnam }\end{array}$ & 8 & 253592 & 12.5 \\
\hline Gissler/2003 & Sweden, national & PBR & 1987-8 & Finland & 6 & 140390 & 23.8 \\
\hline Gould/2003 & USA, California State & PBR & $1995-7$ & India, Mexico & 4 & 1057977 & 42.2 \\
\hline \multirow[t]{2}{*}{ Guendelman/1999 } & Belgium, national & PBR & 1992 & North Africa & 2 & 107968 & 4.3 \\
\hline & France, national & PBS & 1995 & North Africa & 2 & 11802 & 5.4 \\
\hline Rasmussen/1995 & Sweden, national & PBR & $1978-90$ & $\begin{array}{l}\text { West Europe/north America, east Europe, } \\
\text { north Africa/Middle East, sub-Saharan } \\
\text { Africa, Latin America }\end{array}$ & 8 & 1258021 & 11.3 \\
\hline Rosenberg/2005 & USA, New York City & PBR & $1996-7$ & Latin America & 12 & 78042 & 58.8 \\
\hline Vangen/2002 & Norway, national & PBR & $1980-95$ & Pakistan, Vietnam, north Africa & 4 & 820256 & 1.4 \\
\hline Wingate/2006 & USA, national & PBR & $1995-9$ & Latin America (Mexico) & 4 & 2446253 & 61.5 \\
\hline Total & & & & & 143 & 31021461 & 19.9 \\
\hline
\end{tabular}

HR, hospital record; LBW, low birth weight; PB, population-based; PBR, population-based registry; PBS, population-based survey.

countries, because some studies ${ }^{15} 88$ have grouped these regions together. Sensitivity analyses performed without these two studies did not affect the results regarding north Africans and therefore we did not exclude them.

\section{Statistical analyses}

In order to account for the potential heterogeneity between studies and subgroups within studies, we employed random effects meta-regression analysis, which involves the application of multilevel methods to meta-analysis. ${ }^{92-94}$ We used three-level models, with births at level 1, subgroups at level 2 and studies at level 3 . The inclusion of random effects at the subgroup level assumes that each subgroup represents a different population with its own distribution. Ignoring the hierarchical structure of these data would produce over-precise confidence intervals. ${ }^{95} 96$ Analyses were conducted using Proc GLIMMIX in SAS version 9.1 to fit multilevel logistic regression models for summary data.

In the first meta-analysis (migration and race/ethnicity) we fitted two models for each outcome: the first model had migrant status as the only predictor and a more complex model added race/ethnicity and a product term between race/ethnicity and migrant status to obtain odds ratios (OR) simultaneously comparing minority groups with whites, by migrant status, and foreign-born with native-born within ethnic groups. All models were adjusted for infants' year of birth. We quantified the percentage of variance explained for logistic models by comparing the more complex model relative to the model including migrant status as the only predictor. ${ }^{97}$

The second meta-analysis (migration and world regions) was based on studies that analysed LBW in Europe or the USA, categorising migrants and non-migrants by their countries of birth, irrespective of their race/ethnicity. We could not analyse PTB due to the small number of studies and migrant groups. The LBW model included a product term between world region of origin and place of destination (Europe vs USA) in order to test the hypothesis that the odds of LBW differ both according to the region of origin and destination, adjusted for infants' year of birth. p Values less than 0.10 were considered statistically significant for product terms.

\section{RESULTS}

\section{Migration and race/ethnicity}

We first fitted a three-level model with migrant status as the independent variable, adjusted for infant's year of birth, but ignoring race/ethnicity. The OR (95\% CI) for the comparisons between migrants and non-migrants were 0.81 (0.70 to 094) for LBW and 0.85 (0.74 to 0.98 ) for PTB, respectively. These are inappropriate models that assume that the effect of migrant status can be averaged across racial/ethnic groups. Instead, table 3 shows the results of the three-level models including race/ ethnicity and a product term between race/ethnicity and migrant status for the two outcomes, adjusted for year of birth. The $p$ values of the product term for the models of LBW and PTB were 0.0611 and 0.0018 , respectively. The percentage of total variance explained by the introduction of race/ethnicity and the product term 'migrant status $\times$ race/ethnicity' relative to a model including only migrant status, adjusted for year of birth, was $57 \%$ and $24 \%$ for LBW and PTB, respectively, suggesting that race/ethnicity and its interplay with migrant status explain substantial variability in the outcomes not accounted for by migrant status alone.

The first, second and third columns of $\mathrm{OR}$ in table 3 present ethnic disparities within first-generation migrants, within US-born, and disparities between foreign-born and US-born of the same ethnic group, respectively.

Among foreign-born migrants, all minority groups were more likely to have adverse birth outcomes than white women, with the exception of Hispanic migrants for LBW. Black women were the group at the highest odds for the two outcomes both among foreign-born and US-born women. Despite baseline LBW 
Table 2 Characteristics of the US studies included in the meta-analysis by race/ethnicity

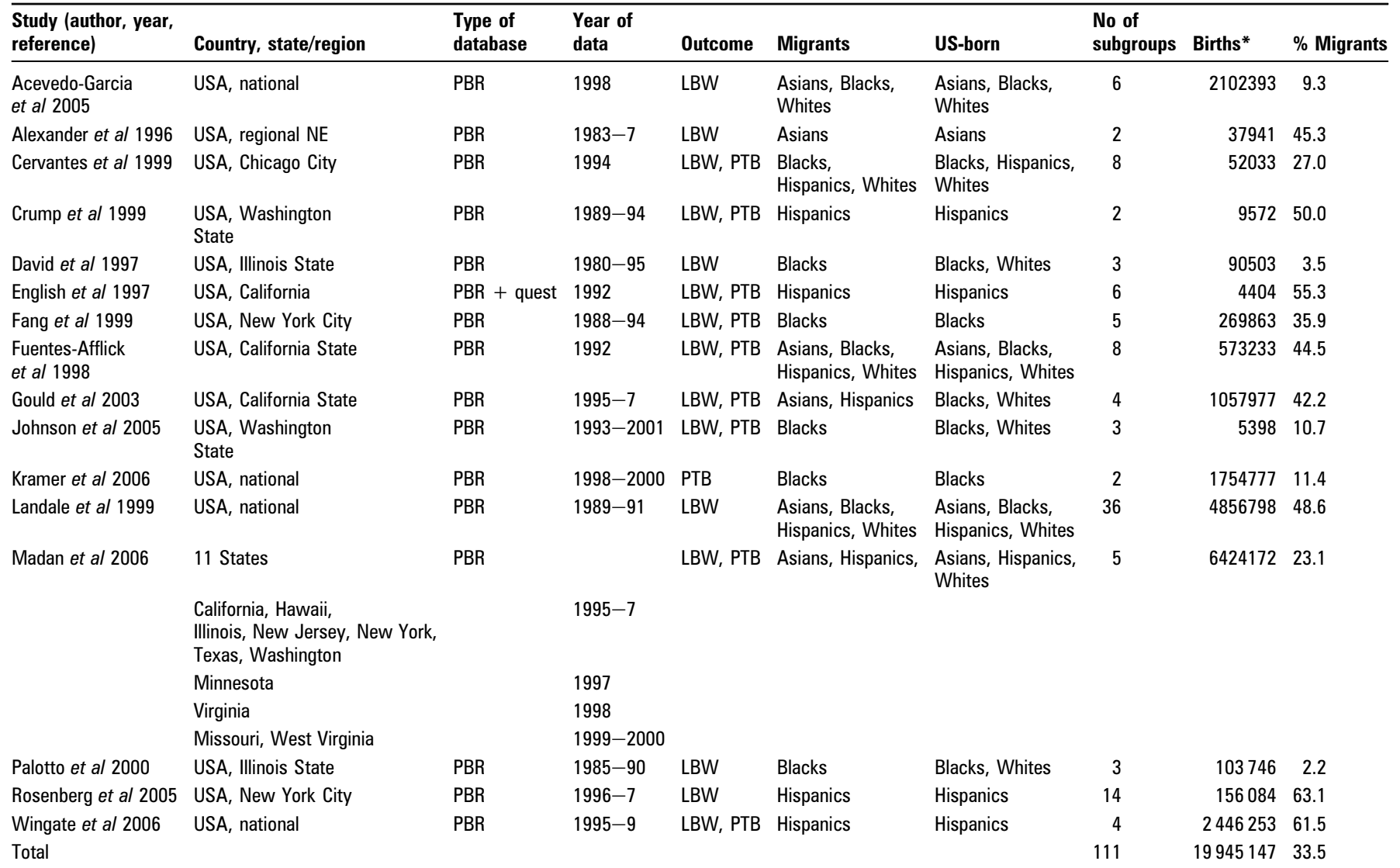

HR, hospital record; LBW, low birth weight; PB, population-based; PBR, population-based registry; PBS, population-based survey; PTB, preterm birth; Quest, questionnaire.

*When the sample size varies by outcome, the denominator for LBW was reported, followed by PTB if LBW was not reported.

and PTB rates that were higher for native-born white women compared with white migrants, the black-white gap was wider among the US-born than among international migrants. Conversely, the Asian-white gap narrowed among the US-born compared with first-generation migrants, and there was no evidence that foreign-born Asian women were protected for these outcomes compared with US-born Asian women. Black women presented the strongest protective effect of being foreign born for the two outcomes, followed by Hispanic women (last column). The Hispanic-white gap was wider among the native-born than among the foreign-born women in LBW but not in PTB.

Table 3 Percentage and OR (and 95\% $\mathrm{Cl}$ )* for adverse birth outcomes for ethnic minority women compared with white women, by migrant status; and OR of migrants compared with US-born women, by ethnic group

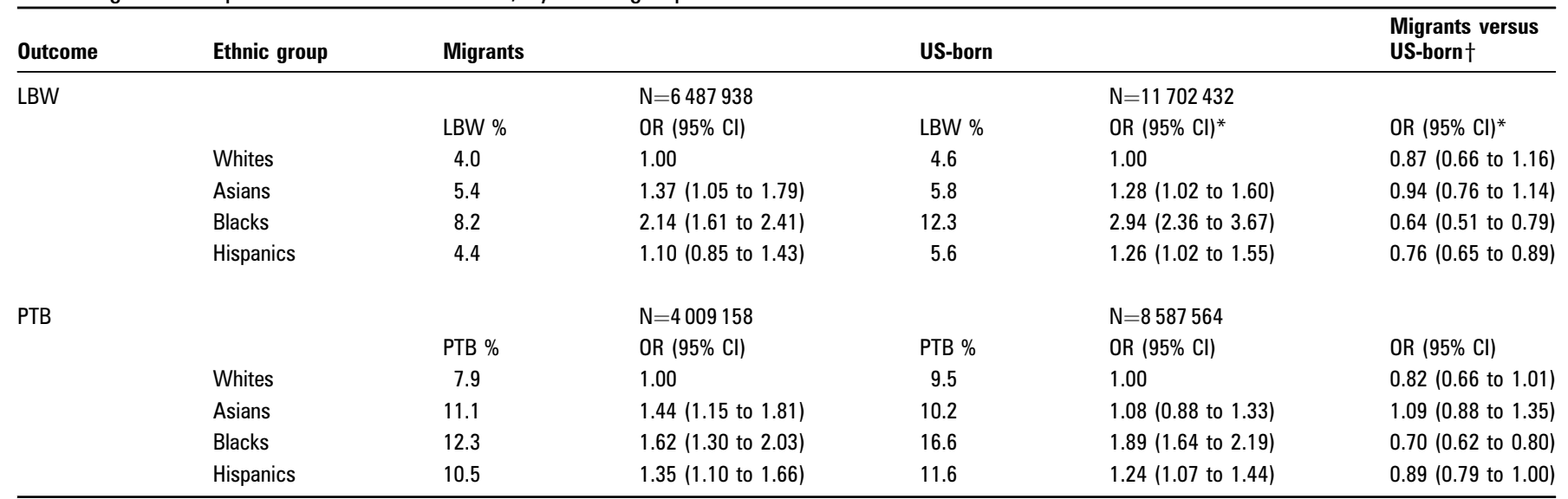


Table 4 Infants and percentage of LBW infants born in Europe and the USA, by migrant group

\begin{tabular}{|c|c|c|c|c|}
\hline \multirow[b]{2}{*}{ Migrant group } & \multicolumn{2}{|c|}{ Infants born in Europe } & \multicolumn{2}{|c|}{ Infants born in the USA } \\
\hline & Births & LBW \%* & Births & LBW \%* \\
\hline Native-born women & 13439223 & 4.3 & 11395215 & 6.9 \\
\hline Western Europe and north America & 284372 & 3.9 & - & - \\
\hline East Europe & 40224 & 4.3 & - & - \\
\hline North Africa/Middle East & 62622 & 3.4 & - & - \\
\hline Sub-Saharan Africa & 172936 & 7.3 & 13076 & 5.3 \\
\hline East/south-east Asia & 3283 & 5.1 & 328713 & 6.2 \\
\hline Latin America/Caribbean & 67788 & 6.2 & 4613040 & 5.0 \\
\hline
\end{tabular}

LBW, low birth weight.

*Obtained with a three-level model including random effects (subgroup and studies) and fixed effects (migrant status, maternal region of origin, place of destination, maternal region of origin $\times$ place of destination and infant's year of birth).

\section{Migration and world regions}

This meta-analysis is based on 16 studies that measured foreignborn status and country or region of birth, irrespective of their ethnicity (Table 1). Tables 4 and 5 present the results of a threelevel model of LBW assessing the interaction between world region of origin and destination, which was highly significant $(p<0.0001)$. A few comparisons were not possible because some subgroups migrating to the USA were not represented in the selected studies. Table 4 shows the LBW percentage as predicted by the model, by migrant subgroup.

Table 5 presents OR for LBW according to maternal region of origin and destination. Women from western countries and north Africa compared favourably with European-born women but there were no data available for the USA. Women from sub-Saharan Africa and Latin America and the Caribbean were at higher odds of LBW if migrating to European countries but at lower odds if migrating to the USA, compared with the respective native-born women. Unlike other groups, south-central Asian women were at higher odds in both contexts but the association was stronger in Europe. The direction and strength of these associations are affected by the different baseline risk of the European and US reference groups, with European-born women less likely to deliver LBW infants compared with US-born women (OR 0.61, 95\% CI 0.47 to 0.79). Despite this, sub-Saharan African and Latin-American and Caribbean women migrating to Europe seemed to be more likely to deliver LBW babies compared with those from the same region who migrated to the USA, although these trends did not reach statistical significance in the three-level model (table 5 , third column).

\section{DISCUSSION \\ Main findings}

One of the main findings of this systematic review is that the association between foreign-born status and birth outcomes is not uniform but depends on the migrant subgroup, either defined by a combination of maternal race/ethnicity and migrant status or by the world region of origin and actual destination. We found that infants born to first-generation black and Hispanic migrant women were at lower risk of adverse birth outcomes than their US-born counterparts, but did not find evidence of such protective effect among Asian and white women. Migrants from these ethnicities were at higher risk than white migrants overall. Regarding subgroups defined by region of origin, sub-Saharan African and Latin-American and Caribbean migrants were at higher odds of LBW in Europe but not in the USA, and south-central Asians were at higher odds in both continents.

\section{Strengths and limitations}

Unlike most meta-analyses of observational studies, instead of combining adjusted OR we used summary data stratified by key predictors. This approach made it possible to examine comparisons not explored in previous studies, such as the assessment of ethnic disparities by migrant status and comparisons within

Table 5 OR (and 95\% CI)* for LBW for migrant women compared with European-born and US-born women, and for various world regions according to their place of destination (Europe vs USA)

\begin{tabular}{|c|c|c|c|}
\hline Migrant group & $\begin{array}{l}\text { Infants born in Europe } \\
\text { OR }(95 \% \mathrm{CI})\end{array}$ & $\begin{array}{l}\text { Infants born in USA } \\
\text { OR }(95 \% \mathrm{CI})\end{array}$ & $\begin{array}{l}\text { Infants born take } \\
\text { over in Europe } \\
\text { take over versus } \\
\text { in USA } \dagger \\
\text { OR }(95 \% \text { CI) }\end{array}$ \\
\hline Native-born women & 1.00 & 1.00 & $0.61(0.47$ to 0.79$)$ \\
\hline \multicolumn{4}{|l|}{ Migrants from } \\
\hline Western Europe and north America & 0.91 (0.77 to 1.07 ) & - & - \\
\hline Sub-Saharan Africa & 1.75 (1.44 to 2.12 ) & 0.75 (0.55 to 1.02$)$ & $1.42(0.95$ to 2.14$)$ \\
\hline South-central Asia & 1.84 (1.54 to 2.20$)$ & 1.33 (1.01 to 1.77$)$ & $0.84(0.57$ to 1.23$)$ \\
\hline East and south-east Asia & $1.20(0.72$ to 2.02$)$ & $0.89(0.73$ to 1.09$)$ & $0.82(0.46$ to 1.46$)$ \\
\hline Latin America and Caribbean & $1.46(1.17$ to 1.83$)$ & $0.72(0.62$ to 0.82$)$ & $1.24(0.90$ to 1.72$)$ \\
\hline
\end{tabular}


migrant subgroups according to their place of destination. Another advantage is that our analyses used the same set of covariates and definitions for each study, thus making interpretation of results less problematical than in meta-analyses based on effect estimates adjusted for a varying number of covariates with heterogeneous definitions. However, the limitation of our approach was the inability to extract birth data stratified by potential confounders.

Immigration policies in the receiving countries and social class dynamics in the source countries may favour the selection of women or couples for migration, based on certain characteristics for which distributions may differ both from those of the source and the receiving population (eg, maternal age, maternal and paternal social class, marital status, overall health) and that are also associated with birth outcomes. For example, differences in maternal age may explain part of the foreign-born advantage of Hispanic women in the USA, as they have lower teenage pregnancy rates than their US-born counterparts. ${ }^{79} 82$ Foreign-born Hispanic and black women had lower proportions of single mothers. ${ }^{5} 7982$ Despite these favourable characteristics foreignborn Mexican women but not foreign-born black women in the USA had lower education, less prenatal care and lower income compared with US-born mothers. ${ }^{513} 16$ This phenomenon makes up part of the so-called 'Latino paradox', 17646985 which can also be extended to the birth weight advantage of north African women in France and Belgium. ${ }^{25} 76$ It is clear that any adjusting for risk factors should be undertaken with caution because the same factors cannot be assumed to have the same effects in different populations or different contexts.

As the social and historical complexity involved in each migrant population could not be adequately explored in a metaanalysis searching for overarching trends, our findings should be regarded as global tendencies that may not apply to particular migrant subgroups settling in particular countries, regions, or cities. Part of such complexity involves heterogeneity of source countries within ethnic and migrant subgroups. In addition, ethnic groups differ according to generational status, with US-born Hispanic and Asian women more likely to be first or second generation than US-born black or white women, who are mostly fourth or higher generation. ${ }^{98}$ Even first-generation migrants may differ in their risk of adverse birth outcomes according to their length of residence in the receiving country, information that was rarely collected. ${ }^{16} 6588$

Another potential source of bias is measurement error, mainly resulting from self-reported race/ethnicity and country of birth and nationality in birth certificates. Validation studies suggest that the misclassification is less than $10 \%$ for any ethnic group. ${ }^{99} 100$ The meaning and limitations of the racial/ethnic classification for epidemiological research had been extensively discussed. $^{101} 102$ The reviewed literature on birth outcomes tended to consider the racial/ethnic categories as markers for a social process external to individual physiology rather than indicators of biological types.

\section{Migration and ethnic disparities}

The protective effect in the immigrant generation has a clear gradient: It is stronger for black migrants, still present among Hispanic migrants, but virtually absent among Asian and white migrants. This gradient mirrors the ethnic group hierarchy in the USA, which places people of African descent at the bottom, Hispanic individuals in the middle, and gives (east) Asian individuals a favourable treatment close to that of white individuals. ${ }^{103} 104$ These findings are at odds with the classic assimilation theory that predicts a convergence of the outcomes of migrant groups towards the level observed in the mainstream white society. ${ }^{105}$ Instead, the observed pattern is more consistent with the segmented assimilation theory that suggests that migrants are selectively incorporated into the system of stratification of the American society based on their ethnic affiliation. ${ }^{104}$

The better birth outcomes of foreign-born black women compared with their US-born counterparts cannot be explained by the 'genetic hypothesis', which would predict that US-born black women be an intermediate risk group between foreign-born black and US-born white women because of intermarriage and genetic mixing over previous generations. ${ }^{4} 18$ Among the environmental explanations, assimilation theories cannot fully account for US-black disadvantage, because these theories focus on how migrants and their offspring are incorporated into the host society ${ }^{104} 105$ and approximately $97 \%$ of US-born black individuals were fourth or higher generation in $1990 .{ }^{98} \mathrm{~A}$ few studies have proposed a sociohistorical hypothesis, pointing to continuous exposure to socioeconomic and structural discrimination, ${ }^{58} 84106$ from past historical periods to the urban underclass. Such explanation is consistent with a substantial sociological literature indicating that racial segregation concentrates deprivation in black neighbourhoods by concentrating people who fit negative racial stereotypes and by restricting the poverty created by economic downturns into a small number of visible minority neighbourhoods, mainly through discrimination in the housing market. ${ }^{107} 108$ Residential racial segregation has been positively associated with infant mortality among black individuals but negatively among white individuals, ${ }^{109}$ and the black-white gap in PTB was found to be higher in hypersegregated areas. ${ }^{110}$

Because international migration barely contributes to the number of black people in the USA, the relative advantage of foreign-born black individuals has little impact on the birth outcomes of black individuals as a whole. In contrast, migrant women contributed to nearly $60 \%$ of births among Hispanic individuals, thus shaping the birth outcomes of this ethnic group.

\section{Migration and region of origin and destination}

Regarding subgroups defined by region of origin and destination, sub-Saharan African and Latin-American and Caribbean migrants were at higher odds of LBW in Europe but not in the USA, and south-central Asian individuals were at higher odds in both continents, although their disadvantage was somewhat attenuated in the USA. Part of these differences can be explained by the ethnic composition of the native-born populations in these analyses, defined by their place of birth but not by their ethnic groups and by the patterns of emigration. Therefore, US-born individuals compare unfavourably with European-born individuals partly due to the heavier weight of their ethnic minorities. In the same vein, the Latin-American advantage in the USA may be driven by the disproportionate representation of Mexican people in the USA, but not in Europe. LBW rates of Mexican individuals were among the lowest among LatinAmerican immigrants. ${ }^{85}$ It is believed that Mexican individuals in the USA are protected because of their residential proximity with co-ethnics, social support systems and cultural orientation, ${ }^{16} 1779111$ all of which is facilitated by the spatial contiguity with the home country. The safeguarding of such protective traits may be more difficult to achieve in transatlantic Europe.

The reasons for the higher odds of LBW of sub-Saharan African women in Europe compared with those settling in the USA are not clear. Differential migration could not be assessed because, with one exception, ${ }^{83}$ studies did not provide 


\section{What is already known on this subject}

- Immigrant women contribute more than one fifth of all live births in several industrialised countries.

- Studies comparing birth outcomes of migrants with those of native-born women show mixed results.

\section{What this study adds}

- The use of foreign-born status as a single category is not informative.

- Compared with native-born women, sub-Saharan African and Latin-American and Caribbean migrants were at higher odds of LBW in Europe but not in the USA, and south-central Asian women were at higher odds in both continents.

- The direction and strength of the associations between foreignborn status and birth outcomes depend on the choice of the reference group and on the definition of the migrant subgroup, either defined by maternal race/ethnicity, world region of origin and place of destination.

information at the country level. It is unlikely that the distribution of reported risk factors accounts for the difference, because the rates of anaemia, tobacco smoking, marital status, maternal education and low income were comparable in both continents. ${ }^{4} 15258183$ Unmeasured factors or a differential effect of the receiving environments probably plays a role. The same receiving environment may also affect some migrant groups favourably and others unfavourably, as suggested in a Swedish study. ${ }^{88}$

\section{Further research}

It remains to be determined whether and to what extent the risk of adverse birth outcomes differs for particular migrant groups according to their actual destination and whether such an effect, if existent, is due to selective migration or to differential exposures in the receiving environment. The existence of differences in the risk of adverse birth outcomes within migrant groups according to place of migration remains a plausible hypothesis to be investigated further.

Our analyses imply that the definition of the migrant groups and the choice of the reference groups have a decisive impact on the direction and strength of the effect estimates for the migrant groups. Although the comparison between migrants and majority populations may be of interest in itself for highlighting disparities by migrant status as a single category, summary statistics representing the effect of foreign-born status may result in misleading conclusions regarding particular migrant groups. Future research should thus strive to distinguish subgroups defined by their regions and, when feasible, by their countries of origin because there may be heterogeneity between countries within the same world region. ${ }^{22} 85$ Distinguishing appropriate comparison subgroups within the receiving-country population is also recommended, especially in countries highly stratified by race/ethnicity such as the USA. ${ }^{101}$

Further research on migration and adverse birth outcomes may advance knowledge by examining why some migrant groups experience poor outcomes and why others do not and what are the dynamics leading to worse outcomes among the offspring of some migrant groups but not of others. Future studies will benefit from obtaining longitudinal measurements on migrants, including premigration characteristics and circumstances of immigration, and social environment, medical care and health behaviour after arrival.

Acknowledgements The authors thank Rahim Moineddin for his help on statistical issues and John Frank for his comments on an earlier version of the manuscript.

Funding This work was partly funded by the Canadian Institutes of Health Research (ClHR) under their International Opportunities Program (157033 to AG) with start-up support from Immigration et métropoles (Center of Excellence in Immigration Studies, Montreal), and by personal research grant (CIHRIOP-44972 to MU) of Dr John Frank, Scientific Director of the Institute of Population and Public Health of the Canadian Institutes of Health Research. Le fonds de la recherche en santé du Québec (FRSO) provided career support and l'Institut national de la santé et de la recherche médicale (INSERM; France), a visiting scientist scholarship (to AG)

Competing interests None.

Provenance and peer review Not commissioned; externally peer reviewed.

\section{REFERENCES}

1. United Nations Population Fund (UNFPA). State of World Population 2006. A Passage to Hope: Women and International Migration. New York: UNFPA, 2006.

2. Centers for Disease Control and Prevention (CDC). State-specific trends in U.S live births to women born outside the 50 states and the District of Columbia United States, 1990 and 2000. MMWR Morb Mortal Wkly Rep 2002;51:1091-5

3. Sobotka T. Overview chapter 7: the rising importance of migrants for childbearing in Europe. Demogr Res 2008;19(Article 9):225-48.

4. David RJ, Collins JW Jr. Differing birth weight among infants of U.S.-born blacks African-born blacks, and U.S.-born whites [comment]. N Engl J Med 1997;337:1209-14.

5. Acevedo-Garcia D, Soobader MJ, Berkman LF. The differential effect of foreignborn status on low birth weight by race/ethnicity and education. Pediatrics 2005; 115:e20-30.

6. Wingate MS, Alexander GR. The healthy migrant theory: variations in pregnancy outcomes among US-born migrants. Soc Sci Med 2006;62:491-8.

7. Bollini P, Pampallona S, Wanner P, et al. Pregnancy outcome of migrant women and integration policy: a systematic review of the international literature. Soc Sci Med 2009;68:452-61.

8. Stroup DF, Berlin JA, Morton SC, et al. Meta-analysis of observational studies in epidemiology: a proposal for reporting. Meta-analysis of observational studies in epidemiology (MOOSE) group. JAMA 2000;283:2008-12.

9. Harris RP, Helfand M, Woolf SH, et al. Current methods of the US Preventive Services Task Force: a review of the process. Am J Prev Med 2001;20:21-35.

10. Cocroft JR, Hauck WW, Cosler L, et al. The effect of ethnicity and maternal birthplace on small-for-gestational-age deliveries to HIV-infected women. J Urban Health 2002;79:147-60.

11. Gissler M, Pakkanen M, Olausson PO. Fertility and perinatal health among Finnish immigrants in Sweden. Soc Sci Med 2003;57:1443-54.

12. Gould JB, Madan A, Oin C, et al. Perinatal outcomes in two dissimilar immigrant populations in the United States: a dual epidemiologic paradox. Pediatrics 2003;111:e676-82.

13. Madan A, Palaniappan L, Urizar G, et al. Sociocultural factors that affect pregnancy outcomes in two dissimilar immigrant groups in the United States. J Pediatr 2006;148:341-6.

14. Dejin-Karlsson $\mathbf{E}$, Ostergren PO. Country of origin, social support and the risk of small for gestational age birth. Scand J Public Health 2004;32:442-9.

15. Essen B, Hanson BS, Ostergren PO, et al. Increased perinatal mortality among sub-Saharan immigrants in a city-population in Sweden. Acta Obstet Gynecol Scand 2000; 79:737-43.

16. Crump C, Lipsky S, Mueller BA. Adverse birth outcomes among MexicanAmericans: are US-born women at greater risk than Mexico-born women? Ethn Health 1999;4:29-34

17. Landale NS, Oropesa Gorman BK. Immigration and infant health: birth outcomes of immigrant and native-born women. In: Children of immigrants: health, adjustment and public assistance. Washington, DC: National Academy Press, 1999:244-85. http:// www.nap.edu/openbook.php?record id =9592\&page $=224$

18. Kramer MS, Ananth CV, Platt RW, et al. US Black vs white disparities in foetal growth: physiological or pathological? Int J Epidemiol 2006;35:1187-95.

19. National Center for Health Statistics. Technical Appendix. Vital Statistics of the United States, 2002, natality. Hyattsville, Maryland: National Center for Health Statistics, 2003. http://www.nber.org/perinatal/2002/docs/techap02.pdf

20. European Parliament. Directive 95/46/EC of the European Parliament and of the Council of 24 October 1995 on the protection of individuals with regard to the processing of personal data and on the free movement of such data. Official J Eur Communities 1995;281:31. http://ec.europa.eu/justice_home/fsj/privacy/docs/9546-ce/dir1995-46_part1_en.pdf

21. Harding S, Rosato MG, Cruickshank JK. Lack of change in birthweights of infants by generational status among Indian, Pakistani, Bangladeshi, Black Caribbean, and Black African mothers in a British cohort study. Int J Epidemiol 2004;33:1279-85. 
22. Fuentes-Afflick $\mathbf{E}$, Hessol NA. Impact of Asian ethnicity and national origin on infant birth weight. Am J Epidemiol 1997;145:148-55.

23. Collingwood BA. Trends in live births by mother's country of birth and other factors affecting low birthweight in England and Wales, 1983-2001. Health Stat 0 2004;23:25-33.

24. Delvaux T, Buekens $\mathrm{P}$, Thoumsin $\mathrm{H}$, et al. Cord $\mathrm{C}$-peptide and insulin-like growth factor-I, birth weight, and placenta weight among North African and Belgian neonates. Am J Obstet Gynecol 2003;189:1779-84.

25. Gayral-Taminh M, Arnaud C, Parant 0, et al. Pregnancy and labor of women born in Maghreb and Black Africa followed to delivery at the Maternity Hospital of Toulouse. J Gynecol Obstet Biol Reprod (Paris) 1999;28:462-71.

26. Harding S, Boroujerdi M, Santana P, et al. Decline in, and lack of difference between, average birth weights among African and Portuguese babies in Portugal [comment]. Int J Epidemiol 2006:35:270-6.

27. Harding S, Santana P, Cruickshank JK, et al. Birth weights of black African babies of migrant and nonmigrant mothers compared with those of babies of European mothers in Portugal. Ann Epidemiol 2006:16:572-9.

28. Margetts BM, Mohd YS, Al Dallal Z, et al. Persistence of lower birth weight in second generation South Asian babies born in the United Kingdom. J Epidemiol Community Health 2002:56:684-7.

29. Moore WM, Bannister RP, Ward BS, et al. Fetal and postnatal growth to age 2 years by mother's country of birth. Early Hum Dev 1995;42:111-21.

30. Rizzo N, Ciardelli V, Gandolfi CG, et al. Delivery and immigration: the experience of an Italian hospital. Eur J Obstet Gynecol Reprod Biol 2004;116:170-2.

31. Roville-Sausse F, Truc JB, Jacob D. Maternal weight gain during pregnancy in various immigrant communities living in France. Rev Epidemiol Sante Publique 2001; 49:439-47

32. Vangen S, Stray-Pedersen B, Skrondal A, et al. High risk of cesarean section among ethnic Filipinos: an effect of the paternal contribution to birthweight? Acta Obstet Gynecol Scand Supp/ 2003;82:192-3

33. Zambrana RE, Scrimshaw SC, Collins N, et al. Prenatal health behaviors and psychosocial risk factors in pregnant women of Mexican origin: the role of acculturation. Am J Public Health 1997;87:1022-6.

34. Bona G, Zaffaroni M, Cataldo F, et al. Infants of immigrant parents in Italy. A national multicentre case control study. Panminerva Med 2001;43:155-9.

35. Burton AJ, Lancaster P. Obstetric profiles and perinatal mortality among Pacific Island immigrants in New South Wales, 1990-93. Aust NZ J Public Health 1999:23:179-84

36. Checa MA, Peiro R, Pascual J, et al. Drug intake behaviour of immigrants during pregnancy. Eur J Obstet Gynecol Reprod Biol 2005;121:38-45.

37. Dhawan S. Birth weights of infants of first generation Asian women in Britain compared with second generation Asian women [comment]. BMJ 1995; 311:86-8.

38. Diani F, Forestieri C, Foschi F, et al. Assisted labor among non European community pregnant women at the Gynecology and Obstetrics Clinic of the Verona University. Minerva Ginecol 2000;52:447-57.

39. Diani $\mathbf{F}$, Zanconato G, Foschi $\mathrm{F}$, et al. Management of the pregnant immigrant woman in the decade 1992-2001. J Obstet Gynaecol 2003;23:615-17.

40. Forna $\mathbf{F}$, Jamieson DJ, Sanders D, et al. Pregnancy outcomes in foreign-born and US-born women. Int J Gynaecol Obstet 2003;83:257-65.

41. Gunton JE, Hitchman R, McElduff A. Effects of ethnicity on glucose tolerance, insulin resistance and beta cell function in 223 women with an abnormal glucose challenge test during pregnancy. Aust NZ J Obstet Gynaecol 2001:41:182-6.

42. Howard DL, Marshall SS, Kaufman JS, et al. Variations in low birth weight and preterm delivery among blacks in relation to ancestry and nativity: New York City, 1998-2002. Pediatrics 2006:118:e1399-405.

43. Kelaher M, Jessop DJ. Differences in low-birthweight among documented and undocumented foreign-born and US-born Latinas. Soc Sci Med 2002; 55:2171-5

44. Kuvacic I, Skrablin S, Hodzic D, et al. Possible influence of expatriation on perinatal outcome. Acta Obstet Gynecol Scand Supp/ 1996:75:367-71.

45. Lalchandani S, MacQuillan K, Sheil 0. Obstetric profiles and pregnancy outcomes of immigrant women with refugee status [comment]. Ir Med J 2001;94:79-80.

46. Leslie JC, Diehl SJ, Galvin SL. A comparison of birth outcomes among US-born and non-US-born Hispanic women in North Carolina. Matern Child Health $J$ 2006:10:33-8.

47. Lopez Gallego MF, Gomez HT, Manzanares GS, et al. Preterm delivery and immigration. Ciencia Ginecologika 2005:9:203-8.

48. Manganaro R, Mami C, Palmara A, et al. [Health status of neonates born to immigrants at the University Polyclinic of Messina in 1993-1998. A case-control study]. Pediatr Med Chir 2000;21:197-8.

49. Martin II, Lopez Vilchez MA, Lozano BJ, et al. [Perinatal outcomes in immigrant women]. An Pediatr (Barc) 2006;64:550-6.

50. Medda E, Baglio G, Guasticchi G, et al. [Reproductive health of immigrant women in the Lazio region of Italy]. Ann Ist Super Sanita 2002;38:357-65.

51. Miceli M, Di Lallo D. [The reproductive health of immigrant women: a study in the city of Rome in 1982-1992]. Epidemiol Prev 1996;20:80-2.

52. Mitchell J, Mackerras D. The traditional humoral food habits of pregnant Vietnamese-Australian women and their effect on birth weight. Aust J Public Health 1995; 19:629-33.
53. Nedic B, Loncar $S$, Ravic J, et al. [Deliveries in the outpatient birthing facility in Ruma during 1989 and between 1992 and 1995]. Med Preg/ 1999;52:53-6.

54. Perez CS, Munoz AN, Robledo SA, et al. [Characteristics of immigrant women and their neonates]. An Pediatr (Barc) 2004;60:3-8.

55. Porta RP, Lukic A, Nobili F. Ten year survey of the deliveries of immigrant women residing in Rome. Int J Gynaecol Obstet 1996;52:281-2.

56. Rumbaut R, Weeks J. Unraveling a public health enigma: why do immigrants experience superior perinatal health outcomes. Res Sociol Health Care 1996;13B:337-91.

57. Sarnoff R, Adams E. Racial and ethnic disparities in the discordance between women's assessment of the timing of their prenatal care entry and the first trimester standard. Matern Child Health J 2001:5:179-87.

58. Singh GK, Yu SM. Adverse pregnancy outcomes: differences between US- and foreign-born women in major US racial and ethnic groups. Am J Public Health 1996;86:837-43.

59. Stoltenberg C, Magnus P. Children with low birth weight and low gestational age in Oslo, Norway: immigration is not the cause of increasing proportions. J Epidemiol Community Health 1995; $\mathbf{4 9 : 5 8 8 - 9 3 . ~}$

60. Sullivan J. Vietnamese and Australian birth outcomes. Aust Nurs J 1998;5:33.

61. Versi E, Liu KL, Chia P, et al. Obstetric outcome of Bangladeshi women in east London. Br J Obstet Gynaecol 1995;102:630-7.

62. Yoong W, Wagley A, Fong C, et al. Obstetric performance of ethnic Kosovo Albanian asylum seekers in London: a case-control study. J Obstet Gynaecol 2004;24:510-12.

63. Yoong W, Kolhe S, Karoshi M, et al. The obstetric performance of United Kingdom asylum seekers from Somalia: a case-control study and literature review. Int J Fertil Womens Med 2005;50:175-9.

64. Fuentes-Afflick E, Hessol NA, Perez-Stable EJ. Testing the epidemiologic paradox of low birth weight in Latinos. Arch Pediatr Adolesc Med 1999;153:147-53.

65. Guendelman S, English PB. Effect of United States residence on birth outcomes among Mexican immigrants: an exploratory study. Am J Epidemiol 1995;142 (9 Suppl):S30-8.

66. Hessol NA, Fuentes-Afflick E. The perinatal advantage of Mexican-origin Latina women. Ann Epidemiol 2000:10:516-23.

67. Lauderdale DS. Birth outcomes for Arabic-named women in California before and after September 11. Demography 2006;43:185-201.

68. Berkowitz GS, Blackmore-Prince C, Lapinski RH, et al. Risk factors for preterm birth subtypes. Epidemiology 1998;9:279-85.

69. Buekens P, Notzon F, Kotelchuck $M$, et al. Why do Mexican Americans give birth to few low-birth-weight infants? Am J Epidemiol 2000;152:347-51.

70. Korenbrot CC, Dudley RA, Greene JD. Changes in births to foreign-born women after welfare and immigration policy reforms in California. Matern Child Health $\mathrm{J}$ 2000; 4:241-50

71. Maffeis C, Cavarzere P, Must A, et al. Relationship between immigration fluxes and patterns of small for gestational age in Italy [7]. Acta Paediatr 2005;94:986-8

72. Panagopoulos $\mathbf{P}$, Tsoukalos G, Economou A, et al. Delivery and immigration: the experience of a Greek hospital. Clin Exp Obstet Gynecol 2005;32:55-7.

73. Pearl M, Braveman P, Abrams B. The relationship of neighborhood socioeconomic characteristics to birthweight among 5 ethnic groups in California [see comment]. Am J Public Health 2001;91:1808-14.

74. Reime B, Ratner PA, Tomaselli-Reime SN, et al. The role of mediating factors in the association between social deprivation and low birth weight in Germany. Soc Sci Med 2006;62:1731-44.

75. Foix-L'Helias $\mathbf{L}$, Blondel B. Changes in risk factors of preterm delivery in France between 1981 and 1995. Paediatr Perinat Epidemiol 2000:14:314-23.

76. Vahratian A, Buekens P, Delvaux T, et al. Birthweight differences among infants of North African immigrants and Belgians in Belgium. Eur $\mathrm{J}$ Public Health 2004;14:381-3

77. Zeitlin J, Bucourt M, Rivera L, et al. Preterm birth and maternal country of birth in a French district with a multiethnic population. Br J Obstet Gynaecol 2004;111:849-55.

78. Alexander GR, Mor JM, Kogan MD, et al. Pregnancy outcomes of US-born and foreign-born Japanese Americans. Am J Public Health 1996;86:820-4.

79. Cervantes A, Keith L, Wyshak G. Adverse birth outcomes among native-born and immigrant women: replicating national evidence regarding Mexicans at the local level. Matern Child Health J 1999:3:99-109.

80. English PB, Kharrazi M, Guendelman S. Pregnancy outcomes and risk factors in Mexican Americans: the effect of language use and mother's birthplace. Ethn Dis 1997; 7:229-40.

81. Fang J, Madhavan S, Alderman MH. Low birth weight: race and maternal nativityimpact of community income. Pediatrics 1999;103:E5.

82. Fuentes-Afflick E, Hessol NA, Perez-Stable EJ. Maternal birthplace, ethnicity, and low birth weight in California. Arch Pediatr Adolesc Med 1998:152:1105-12.

83. Johnson EB, Reed SD, Hitti J, et al. Increased risk of adverse pregnancy outcome among Somali immigrants in Washington state. Am J Obstet Gynecol 2005;193:475-82.

84. Pallotto EK, Collins JW Jr., David RJ. Enigma of maternal race and infant birth weight: a population-based study of US-born Black and Caribbean-born Black women. Am J Epidemiol 2000;151:1080-5. 
85. Rosenberg TJ, Raggio TP, Chiasson MA. A further examination of the "epidemiologic paradox": birth outcomes among Latinas. J Natl Med Assoc 2005;97:550-6.

86. Buekens P, Masuy-Stroobant G, Delvaux T. High birthweights among infants of north African immigrants in Belgium. Am J Public Health 1998;88:808-11.

87. Guendelman S, Buekens $\mathrm{P}$, Blondel B, et al. Birth outcomes of immigrant women in the United States, France, and Belgium. Matern Child Health J 1999:3:177-87.

88. Rasmussen F, Oldenburg CE, Ericson A, et al. Preterm birth and low birthweight among children of Swedish and immigrant women between 1978 and 1990. Paediatr Perinat Epidemiol 1995;9:441-54.

89. Vangen S, Stoltenberg C, Skjaerven $\mathrm{R}$, et al. The heavier the better? birthweight and perinatal mortality in different ethnic groups. Int J Epidemiol 2002;31:654-60.

90. United Nations. United Nations World Macro Regions and Components. 2000 http://www.un org/depts/dhl/maplib/worldregions htm (accessed 17 March 2008).

91. United Nations Children's Fund and World Health Organization. Low birthweight: country, regional and global estimates. New York: UNICEF, 2004.

92. Hox J. Multilevel analysis. Techniques and applications. Mahwah, NJ: Lawrence Erlbaum Associates, 2002

93. Raudenbush SW, Bryk AS. Hierarchical linear models. Applications and data analysis methods. 2nd edn. Thousand Oaks, CA: Sage Publications, 2002.

94. Thompson SG, Turner RM, Warn DE. Multilevel models for meta-analysis, and their application to absolute risk differences. Stat Methods Med Res 2001;10:375-92.

95. Thompson SG, Higgins JP. How should meta-regression analyses be undertaken and interpreted? Stat Med 2002;21:1559-73.

96. Higgins JP, Thompson SG. Controlling the risk of spurious findings from metaregression. Stat Med 2004;23:1663-82.

97. Snijders T, Bosker RJ. Multilevel analysis. An introduction to basic and advanced multilevel modeling. London: Sage Publications, 1999.
98. Edmonston B, Passel JS. Immigration and immigrant generations in population projections. Int J Forecast 1992;8:459-76.

99. Baumeister L, Marchi K, Pearl M, et al. The validity of information on "race" and "Hispanic ethnicity" in California birth certificate data. Health Serv Res 2000;35:869-83.

100. Schoendorf KC, Parker JD, Batkhan LZ, et al. Comparability of the birth certificate and 1988 Maternal and Infant Health Survey. Vital Health Stat 20 1993:116:1-19.

101. Kaufman JS, Cooper RS. Commentary: considerations for use of racial/ethnic classification in etiologic research. Am J Epidemiol 2001;154:291-8.

102. Senior PA, Bhopal R. Ethnicity as a variable in epidemiological research. BMJ 1994;309:327-30.

103. Massey DS, Denton NA. Trends in the residential segregation of blacks, Hispanics, and Asians: 1970-1980. Am Sociol Rev 1987;52:802-25.

104. Zhou M. Segmented assimilation: issues, controversies, and recent research on the New Second Generation. Int Migr Rev 1997:31:975-1008.

105. Rumbaut RG. Assimilation and its discontents: between rhetoric and reality. Int Migr Rev 1997:31:923-60.

106. James SA. Racial and ethnic differences in infant mortality and low birth weight. A psychosocial critique. Ann Epidemiol 1993;3:130-6.

107. Massey DS. American Apartheid: segregation and the making of the underclass. Am J Sociol 1990;96:329-57.

108. Massey DS, Gross AB, Shibuya K. Migration, segregation, and the geographic concentration of poverty. Am Sociol Rev 1994;59:425-45.

109. LaVeist TA. Linking residential segregation and infant mortality in U.S. cities. Sociol Soc Res 1989:73:90-4.

110. Osypuk TL, Acevedo-Garcia D. Are racial disparities in preterm birth larger in hypersegregated areas? Am J Epidemiol 2008;167:1295-304

111. Peak C. Weeks JR. Does community context influence reproductive outcomes of Mexican origin women in San Diego, California? J Immigr Health 2002;4:125-36. 